\title{
Cidadania: instrumento e finalidade do processo de trabalho na reforma psiquiátrica
}

\author{
Citizenship: instrument and finality of the working \\ process in psychiatric reform
}

Alice Guimarães Bottaro de Oliveira 1

Neiry Primo Alessi 2

\footnotetext{
1 Departamento de Enfermagem/FAEN Universidade Federal de Mato Grosso/UFMT. Rua Presidente Rodrigues Alves 99/601, Bairro Quilombo, 78043-418, Cuiabá MT.

alicegbo@yahoo.com.br

2 Universidade

de Uberaba/UNIUBE.
}

\begin{abstract}
Within the Brazilian context, starting at the end of the 20th century, the psychiatric reform presented the necessity to rescue the rights of citizenship for the mentally ill. The objective was to analyze citizenship as an instrument and an end of the team work process at six institutions of extra-hospital mental health care belonging to the public network of Cuiabá (MT), in the second semester of 2001. Marxist dialectics was used as the theoretical-methodological framework. It was observed that, even though citizen rights are affirmed for "patients", now called service "users", the paradox between the concept of citizenship and the "mentally ill patient" has not been discussed as a problem and consequently has not resulted in therapeutic attitudes that will permit or insure the participation of professionals and users as citizens. Citizenship is seen as an abstraction, excluded from the sphere of work and/or treatment. In an alienated work there is no explicit consideration of the contradictory situation in which the workers are agents that apply traditionally excluding knowledge and practices and at the same time must go beyond this role and produce practices of psychosocial care that will respect the citizen with mental disorders.
\end{abstract}

Key words Mental health, Working process, Citizenship, Psychiatry, Psychiatric reform
Resumo A reforma psiquiátrica apresentou a necessidade de resgate dos direitos de cidadania para os doentes mentais, no contexto brasileiro, a partir do final do século 20. Busca-se analisar a cidadania como instrumento e finalidade do processo de trabalho das equipes de seis instituições de atenção extra-hospitalar em saúde mental, da rede pública de Cuiabá (M)T, no segundo semestre de 2001. Utiliza-se a dialética marxista como referencial teórico-metodológico. Apesar de se afirmar os direitos de cidadãos para os "pacientes", agora denominados "usuários" dos serviços, o paradoxo entre o conceito de cidadania e "doente mental" não foi problematizado e, portanto, não resulta em atitudes terapêuticas que possibilitem ou assegurem a participação cidadã de profissionais e usuários. A cidadania corresponde a uma abstração, excluída da esfera de trabalho elou tratamento. No trabalho alienado não se explicita a situação contraditória na qual os trabalhadores são agentes que operam saberes e práticas tradicionalmente excludentes e, simultaneamente, necessitam superar esse papel e produzir práticas de atenção psicossocial que respeitem o cidadão portador de transtorno mental.

Palavras-chave Saúde mental, Processo de trabalho, Cidadania, Psiquiatria, Reforma psiquiátrica 


\section{A institucionalização da psiquiatria e a reforma psiquiátrica}

A institucionalização da psiquiatria no mundo ocidental se deu no contexto do Iluminismo, a partir do século 17. A razão dos antigos gregos foi resgatada pelos filósofos dessa época e a irracionalidade, manifesta nos loucos e em muitos outros tipos de "perturbadores da ordem", era contida e corrigida nas prisões, escolas, casas de correção e casas de loucos que surgiram em toda a Europa nos séculos 18 e 19 (Porter, 1990).

Tendo surgido na França, após a Revolução Francesa, a psiquiatria instituiu-se sobre o pano de fundo de uma nova sociedade contratual. Nesta sociedade, o louco é uma nódoa. Insensato, ele não é sujeito de direito; irresponsável, não pode ser objeto de sanções; incapaz de trabalhar ou de servir, não entra no circuito regulado das trocas (Castel, 1978).

Estudos realizados sobre o processo de desenvolvimento desse ramo da ciência médica, embora fundamentados em diferentes paradigmas, apontam para o fato inequívoco: a psiquiatria só se desenvolveu após a criação dos asilos e o corolário da superlotação. Castel (1978) afirma tratar-se de uma "reforma administrativa", como o próprio Philippe Pinel se referiu à sua obra. $\mathrm{O}$ isolamento do mundo exterior, a constituição de um novo ordenamento interno e peculiar ao hospício, com a finalidade de uma correção pedagógica dos internados, foram as bases para a imposição da ordem, a temática principal no trato com os alienados. A respeito da cientificidade da psiquiatria, Castel (1978) afirma que este novo ramo da ciência não provocou nenhuma mudança na organização do saber médico que se constituía, entretanto, soube marcar, com o selo médico, práticas que dizem mais respeito às técnicas disciplinares do que às operaçães de exploração clínica da medicina moderna.

Foi, portanto, neste cenário dos primórdios da modernidade, no qual o homem ocupava a centralidade, a partir do deslocamento de Deus do centro do Universo e no qual a racionalidade humana era reconhecida como a única possibilidade de construção do conhecimento, que surgiu e se institucionalizou a psiquiatria.

O pressuposto da igualdade, na nova ordem jurídica institucional burguesa que se instalava, determinava uma nova função para o Estado. A Nova Declaração dos Direitos do Ho- mem e do Cidadão estabelecia a assistência pública que seria determinada por lei, de acordo com a natureza do problema e a necessidade de intervenção (Castel, 1978). A cidadania era então um atributo dos iguais - racionais, normais. Aos alienados - despossuídos de razão não se cogitava a cidadania, essa entendida como cidadania política liberal, de participação nas decisões sociais.

Por volta da metade do século 20 e, portanto, decorridos um século e meio após o surgimento da psiquiatria, vários movimentos de contestação a este saber e prática instituídos se fizeram notar no cenário mundial, dos quais se destacam os movimentos denominados Psiquiatria de Setor, na França; as Comunidades Terapêuticas, na Inglaterra; e a Psiquiatria Preventiva, nos EUA. Esses movimentos se caracterizaram por visar a uma reforma do modelo de atenção psiquiátrica, constituíram-se em rearranjos técnico-científicos e administrativos da psiquiatria, entretanto, sem a radicalidade da desinstitucionalização proposta pelo movimento italiano a partir de 1960 (Rotelli et al., 1990).

A influência desses movimentos de crítica à psiquiatria também foi notada no contexto social brasileiro, principalmente a partir da década de 1980, no ocaso da ditadura militar e aguda crise econômica que caracterizaram o período. A sociedade reencontrava as vias democráticas de expressão e reivindicação e, neste contexto, as idéias de Foucault, Goffman, Castel, Szasz, Basaglia e outros tiveram uma forte influencia. A situação crítica em que se encontrava a assistência psiquiátrica brasileira, nessa época, marcada pela falência de um modelo privatizante que havia se instalado no setor saúde do País, era favorável à crítica proposta por esses pensadores e por esses movimentos sociais. Os hospitais psiquiátricos, centralizando a assistência e sendo praticamente únicos na oferta de serviços psiquiátricos no contexto nacional, tiveram as condições internas de maustratos aos internados desnudadas e denunciadas no processo social brasileiro de "abertura democrática".

Amarante (1995), propondo uma periodização do movimento de Reforma Psiquiátrica no Brasil, delimita três períodos e denomina este primeiro período, de crítica ao modelo privatizante, de trajetória alternativa desse processo. No segundo período dá-se, segundo o mesmo autor, o momento institucionalizante do processo. Caracteriza-se pela incorporação do 
movimento da Reforma Sanitária e da Reforma Psiquiátrica no aparelho de Estado, na fase de reordenamento político denominado Nova República. A crítica do primeiro período, sobre a cientificidade da medicina/psiquiatria e da neutralidade da ciência, cede espaço para a crença de que a ocupação do aparelho estatal garantiria a mudança paradigmática necessária no setor saúde. O terceiro momento é o de desinstitucionalização do processo. Influenciado pelo movimento italiano, resgata a crítica da institucionalização da psiquiatria e caracterizase pela valorização das micropolíticas, pela reinvenção do cotidiano em experiências localizadas. A desinstitucionalização redefine o objeto de intervenção, as práticas terapêuticas e o objetivo da assistência em saúde mental.

Compreendemos a Reforma Psiquiátrica como um movimento, um processo histórico que se constitui pela crítica ao paradigma médico-psiquiátrico e pelas práticas que transformam e superam esse paradigma, no contexto brasileiro, a partir do final do decênio de 1970, embora com particularidades regionais significativas, no amplo espaço geográfico nacional. Como processo histórico, insere-se numa totalidade complexa e dinâmica, determinada pelos processos sociais, regionais e nacionais, a partir dos anos 80 até a atualidade.

O processo de Reforma Psiquiátrica Brasileiro compreende: a) movimentos populares organizados no sentido de questionar a função social da psiquiatria, dos hospitais psiquiátricos e dos trabalhadores em saúde mental, além de reivindicar direitos dos "doentes mentais"; b) políticas nacionais delineadas principalmente a partir dos anos 90, no setor saúde, estabelecendo uma rede assistencial que apresenta alternativas à internação em hospitais psiquiátricos, e c) legislação nacional e estaduais que garantem um novo modelo assistencial para o atendimento dos problemas de saúde mental da população, além da garantia, aos portadores dos transtornos mentais, dos direitos de cidadania.

A partir dessas considerações sobre a perspectiva histórica do processo de Reforma Psiquiátrica no Brasil, analisaremos as possibilidades de existência dos "direitos de cidadania" dos doentes mentais ao longo dessa trajetória.

\section{A cidadania no Brasil: Aspectos históricos}

A complexidade do conceito de cidadania é consensualmente reconhecida. Carvalho (2002), ao analisar a cidadania no Brasil, afirma que uma cidadania plena está relacionada a um ideal inatingível, desenvolvido pela cultura ocidental, entretanto, não é mera utopia desvinculada da realidade, uma vez que se aplica como parâmetro de avaliação da qualidade da cidadania em cada local e momento histórico. Por cidadania plena, este autor compreende uma combinação de liberdade, participação e igualdade.

Atualmente admite-se, quase que automaticamente, uma relação de cidadania com direitos. Cidadão pleno seria aquele indivíduo titular dos direitos civis (liberdade, igualdade perante a lei e direito de propriedade), políticos (participação no governo da sociedade) e sociais (participação na riqueza coletiva). Segundo Carvalho (2002), a classificação das dimensões de cidadania proposta por Marshall, que se tornou clássica e que teve por base a história da Inglaterra, pressupõe uma evolução linear, em forma de pirâmide em que, a partir da base, inicialmente surgem os direitos civis, em seguida os direitos políticos e, por último, os direitos sociais. Embora sujeita a críticas, essa classificação é ainda utilizada para a compreensão dos direitos de cidadania ao longo da História.

Uma dimensão intrínseca de cidadania é a sua relação com o Estado-nação e o seu surgimento vincula-se diretamente à concepção liberal do Estado. Vieira (2001) afirma que os direitos de cidadania são direitos exercidos no interior de um Estado-nação. Tradicionalmente, o Estado nacional é o lar da cidadania.

Demo (1995) também afirma essa relação cidadania e Estado - e explicita, inclusive, as diferentes concepções de cidadania e direitos num Estado capitalista e socialista. Essa relação torna-se bastante complexa se considerarmos o estágio atual do capitalismo mundial, a "era da globalização” e o predomínio das políticas neoliberais, como abordaremos a seguir, na sua relação com as políticas sociais.

No Brasil, segundo aponta Carvalho (2002), houve uma inversão da lógica e da seqüência descrita por Marshall e "a pirâmide dos direitos foi colocada de cabeça para baixo”. Em nosso País, paradoxalmente, os direitos sociais foram implantados primeiro, em um período de 
repressão dos direitos políticos e de redução dos direitos civis (Era Vargas); os direitos políticos (aumento acentuado dos eleitores) foram expandidos num período ditatorial e os direitos civis continuam ainda hoje inacessíveis à maioria da população. Embora esse mesmo autor considere que não há uma única via de construção do processo de cidadania (garantia de direitos), nem que essa trajetória brasileira possa ser assim tão simplificada, essa inversão deve resultar em diferenças qualitativas importantes na concepção de cidadania. Uma das conseqüências dessa inversão peculiar no caso brasileiro, apontada pelo autor, é o fortalecimento do Executivo, na conformação dos três poderes da República.

Os tipos de cidadania propostos por Demo (1995) são: a) cidadania tutelada, característica do capitalismo perverso, em que o mercado é o regulador absoluto das relações sociais, o Estado é mínimo, conforme a ideologia liberal e, as políticas sociais são setoriais, residuais e têm a função de controle e desmobilização; b) cidadania assistida, característica do welfare state, no qual o mercado é o regulador final das relações sociais, o Estado é máximo, a ideologia é o neoliberalismo e as políticas sociais são setoriais, assistencialistas e visam ampliar os direitos sociais; c) cidadania emancipada, característica de uma sociedade alternativa, na qual o mercado é o meio ou instrumento para a cidadania, o Estado tem o tamanho necessário e legítimo, a ideologia é democrática e as políticas sociais são matriciais e visam ao desenvolvimento humano sustentado. Torna-se evidente o caráter utópico, comparado à realidade brasileira, da cidadania emancipada definida pelo autor.

Ao relacionarmos as três diferentes concepções de cidadania propostas por Demo (1995) ao processo histórico brasileiro de aquisição de direitos, descrito por Carvalho (2002), podemos compreender que a predominância da cidadania assistida, nas últimas décadas do processo político-social brasileiro, pode ser decorrente da inversão da pirâmide dos direitos e do fortalecimento do executivo.

Explicitadas as balizas teóricas - reforma psiquiátrica e cidadania - apresentamos as possibilidades e limites de sua materialização no contexto da sociedade brasileira e suas particularidades no cenário da atenção extra-hospitalar da rede pública de Cuiabá (MT).

\section{A cidadania do doente mental na nova ordem democrática brasileira}

A Reforma Psiquiátrica, no Brasil, foi desencadeada num momento de intensa mobilização social pelo retorno da ordem democrática e foi fortemente influenciada por movimentos de reforma na assistência psiquiátrica na Europa e nos EUA, a partir da segunda metade do século 20.

Birman (1992), analisando esses movimentos europeus e norte-americanos na suas limitações e possibilidades de afirmação da cidadania dos doentes mentais, afirma que os movimentos reformistas denominados comunidade terapêutica e psicoterapia institucional tinham como característica estar circunscritos às instituições psiquiátricas e admitir a participação social dos internados naquela microssociedade. Desta maneira, esses movimentos não superavam o limite fundante da psiquiatria - a impossibilidade de inserção da loucura no espaço social que havia sido conformado excluindo-a - e a cidadania encontrava este limite intransponível.

A psiquiatria de setor (França) e a psiquiatria comunitária (EUA) visavam à ampliação desses movimentos em direção ao espaço social e o último visava ao estabelecimento de práticas psicopedagógicas de saúde mental com objetivos preventivos. Nele, segundo Birman (1992), o projeto político de produção de saúde mental se identificou diretamente com o projeto de produção do cidadão ideal para o espaço social [...] o discurso psiquiátrico se estabeleceu como regulador ativo da marginalidade social e como instituinte das regras básicas da cidadania. [Portanto,] a tentativa de ruptura da psiquiatria com o espaço asilar teve como contrapartida a produção de uma ordem social asilada pela psiquiatria, onde essa regularia a produção de cidadania.

A psiquiatria democrática italiana chocou-se diretamente com o registro da exclusão social da loucura, promovendo a desalienação asilar da loucura com a inserção desta no espaço social. Pretendia-se restaurar a cidadania da loucura, que teria sido retirada após séculos de exclusão social e de violência psiquiátrica (Birman, 1992). Desta maneira, a loucura foi compreendida como uma forma de alienação social e o projeto político de cidadania para os loucos seria a própria estratégia para o seu reconhecimento como sujeitos de razão e de vontade. Esse movimento italiano de desinstitucionalização influenciou a trajetória da Reforma Psiquiátrica no Brasil. 
No contexto social brasileiro, a partir dos anos 80 , sob influência de todos esses movimentos mundiais de reforma e, internamente, a superação da ditadura militar pelo processo de redemocratização, a cidadania foi incorporada à linguagem de movimentos sociais de vanguarda e também na área de saúde e de saúde mental.

Devemos reconhecer que o lento processo de reorganização da sociedade brasileira em direção ao estado de direito, característico desse período, foi eficaz no sentido de absorver importantes demandas sociais da população, traduzindo-as para a norma legal (haja vista a própria promulgação da Constituição cidadã, de 1988), entretanto, a produção de respostas efetivas a essas demandas, é bastante tênue, mesmo tendo-se passado mais de 20 anos.

A referência à cidadania dos doentes mentais está presente nos textos das três Conferências Nacionais de Saúde Mental realizadas no Brasil a partir do final do século 20 (Brasil, 1987; 1992 e 2001) e em inúmeros textos de articuladores técnico-políticos envolvidos com o processo de Reforma Psiquiátrica Brasileira. A cidadania é abordada com enfoques diversificados, referenciados, principalmente, aos diferentes momentos/fases da trajetória da Reforma Psiquiátrica.

Uma característica fundamental do novo "local social" da loucura/doença mental, identificada nessa produção teórica e relacionada diretamente a essa possibilidade de cidadania para os doentes mentais, é a substituição dos termos "doença" e "doente mental" por "sofrimento psíquico" e "pessoas portadoras de sofrimento psíquico". Essa diferença pretendeu (e pretende) ir além de uma mera adequação técnica ou semântica. Trata-se, como consta na descrição dos marcos conceituais da II Conferência Nacional de Saúde Mental, de construir uma mudança no modo de pensar a pessoa com transtornos mentais em sua existência sofrimento, e não apenas a partir de seu diagnóstico (Brasil, 1992), contextualizando o processo saúde/doença mental e vinculando o conceito de saúde ao exercício da cidadania.

Adotando-se a trajetória descrita por Amarante (1995), a produção sobre o debate da cidadania na sua relação com a doença mental, na segunda fase da Reforma Psiquiátrica (institucionalizante), período compreendido principalmente na década de 1980, enfatiza o debate em torno das questões jurídicas, legislativas e as relacionadas ao macro modelo assistencial
(Reforma Sanitária, Constituição Federal, Lei Paulo Delgado), todas referenciadas à uma mudança macro organizacional que garantiria os direitos de cidadão ao louco (Pitta \& Dallari, 1992; Delgado, 1992a; Padrão, 1992). Isso se refere ao momento político - tentativa dos movimentos populares organizados em buscar garantir nos textos legais e oficiais os direitos civis e sociais. Sabemos hoje que não basta a garantia legal ou o documento oficial; cidadania se conquista no cotidiano, nas relações diárias, micro e macrossociais.

As macro-mudanças legislativas, jurídicas e administrativas eram, portanto, nesse período institucionalizante da Reforma Psiquiátrica, consideradas necessárias e, até mesmo, a garantia de operacionalização de novas práticas terapêuticas. O movimento de Reforma Psiquiátrica, na época, admitia a cidadania como relacionada ao resgate da dívida social para com os loucos. Excluídos socialmente ao longo da História, bastaria, pois, que a sociedade abolisse as formas institucionais concretas de exclusão leis restritivas, manicômios, grades - e identificasse "os loucos" como cidadãos iguais perante a lei, para que os seus direitos de cidadania fossem garantidos.

Analisando esse período da Reforma Psiquiátrica, Bezerra Jr. (1994) afirma que a perspectiva de cidadania como sinônimo de igualdade e liberdade apresenta pelo menos dois equívocos: a exclusão pode ser muito mais refinada e sutil (e mais eficaz) do que os muros e grades concretamente identificados no tecido social, e o princípio da igualdade pode se configurar como injusto; não é o caso de tratar todos igualmente, mas de identificar e respeitar as diferenças, pois sempre haverá aqueles para quem a vida é mais difícil, o sofrimento mais penoso e a necessidade de ajuda mais constante (Bezerra Jr., 1994).

A partir de análises que buscam ir além da mera afirmação dos direitos de cidadania como a necessidade daquele momento para a melhoria da assistência aos doentes mentais, Birman (1992), Bezerra Jr (1992) e Delgado (1992b) destacam a situação aparentemente paradoxal implícita na relação cidadania \& doença mental tão presente nos discursos da Reforma Psiquiátrica. Tal paradoxo se explicita na concepção de que a cidadania, fundada em princípios liberalizantes, pressupõe a liberdade e a igualdade como seus atributos básicos, enquanto que a assistência (médica, jurídica) ao doente mental pressupõe o amparo social do Estado, muitas 
vezes incluindo a interdição e a imposição de um tratamento baseado na negação de direitos civis (liberdade). Esse mecanismo de exclusão foi estruturante na psiquiatria, como já referimos anteriormente. E, em sendo estruturante, negá-lo significaria, no limite, negar toda a "instituição-Psiquiatria". Trata-se, portanto, de algo muito mais profundo do que mudanças administrativas e legais, é uma "nova construção social/ cultural", para um "novo objeto". Não mais o doente mental a ser excluído da sociedade, mas a convivência com uma pessoa que pode ser radicalmente diferente dos padrões culturais mas que, ainda assim, pode ter direitos de cidadania, ou seja, de estar "incluído" como sujeito de direitos nesta sociedade. Isso implica alterações profundas nas relações sociais em geral, muito mais amplas do que modificações nas instituições que tratam os doentes mentais (Birman, 1992).

Num terceiro momento da Reforma Psiquiátrica (o da desinstitucionalização), ao compreender a cidadania não mais como um atributo formal, mas um projeto aberto a ser construído cotidianamente e, após reconhecer que no Brasil, nos anos 80 (e ainda hoje), o mais importante não era reivindicar os direitos de cidadania, mas construir essa cidadania, admitiase mais livremente a necessidade de desconstrução do manicômio em todas as suas estruturas - internas e externas. A Reforma Psiquiátrica passou a ser compreendida como um interlocutor indispensável no processo de construção da cidadania brasileira (Bezerra Jr., 1994).

Sinalizando para diferenças significativas, tanto no que se refere à necessidade de se buscar no cotidiano e nas micro-relações a possibilidade de construção de cidadania para os doentes mentais, tanto para o fato de que instituições e técnicas não asseguram direitos de cidadania para doentes mentais, Saraceno (2001) afirma a possibilidade de sua construção como meta e instrumento de reabilitação psicossocial, compreendendo que os seres humanos, os doentes mentais inclusive, atuam em três cenários: habitat, rede social e trabalho com valor social. A habilidade ou "desabilidade" para os exercícios contratuais nessas três esferas de relações é o que deve ser analisado quando se tem em mente a reabilitação. A habilidade do indivíduo em efetuar plenamente suas trocas nesses três cenários é a medida de exercício de sua cidadania, segundo este autor.

Num cenário positivista e funcionalista, que predomina em nossa sociedade para expli- car as relações saúde x doença mental e cidadania \& doença mental tornam-se um enigma indecifrável ou uma barreira intransponível. A percepção dos fenômenos mentais e sociais, aprisionados numa perspectiva evolucionista linear composta de processos mecânicos, é um fator limitante para que se compreenda as amplas e diversas modalidades, etapas e possibilidades, seja de adoecer mentalmente, seja de exercer a cidadania.

A psiquiatria - ciência e prática - funda-se sobre o irreconciliável paradoxo da doença mental versus cidadania, pois apreende a doença mental a partir de uma ordem ou norma desqualificadora. O ser humano desprovido de razão e, portanto, de direitos - doente mental não pode aspirar a condição de exercício de direitos. Há uma contradição intransponível nessa perspectiva.

A Reforma Psiquiátrica, que além de redefinir práticas terapêuticas e administrativas no trato com pessoas que sofrem mentalmente, admite (pelo menos ao nível do discurso oficial programático) um novo lugar social para o sofrimento mental, pode ousar a busca de uma outra relação, a da doença mental $e$ cidadania.

A ampliação da compreensão da cidadania, não mais restrita ao reconhecimento de direitos, mas ao processo ativo de ampliação da capacidade de todos e de cada um agirem de modo livre e participativo (Bezerra Jr., 1992), permite e compõe a idéia de loucura/doença mental não mais como defeito, falha ou desqualificação. Entretanto, as condições sociais a partir das quais é possível (ou impossível) a concretização dessas construções teóricas exigem aprofundamento conceitual e auto-crítica, além de condições objetivas que permitam o seu desenvolvimento. É desse momento de dificuldade relacionada a uma determinação pragmática dos objetivos de serviços de saúde mental, e da necessidade de se manter uma utopia de maior solidariedade humana que estamos falando quando abordamos a cidadania de doentes mentais.

\section{A cidadania dos portadores de sofrimento mental nos serviços de saúde mental}

A superação das práticas custodiais, características do modelo médico de atenção psiquiátrica e centradas no hospital psiquiátrico, rumo ao desenvolvimento de modos de cuidar/tratar voltados para a atenção psicossocial é algo já 
bastante difundido no discurso do movimento de Reforma Psiquiátrica brasileira. Entretanto, serviços extra-hospitalares, na realidade estudada, apenas facilitam, mas não garantem, a execução desse projeto terapêutico inovador.

Conceitos como cidadania, autonomia e socialização se apresentam ainda de modo bastante conflituoso diariamente, no cotidiano das equipes de saúde mental, nas suas relações com os usuários. As concepções de sujeito autônomo, tendo em vista um processo de reabilitação psicossocial, por exemplo, podem ser bastante divergentes, como aponta Saraceno (2001). Portanto, podemos observar, nesse aspecto, concepções teóricas das mais reducionistas às mais ampliadas. Das observações realizadas, podemos considerar alguns exemplos desses conceitos de extremo reducionismo, em situações de cuidado em serviços abertos que poderiam, entretanto, ser canalizadas para um grau elevado de participação e decisão dos sujeitos/usuários se estivessem inseridas em projetos terapêuticos democráticos:

Relato de Observação - Serviço № 2 Dois profissionais trouxeram pipoca e limão para que os usuários fizessem um lanche. Explicam que de vez em quando planejam isto às sextas-feiras, com ou sem a participação dos usuários nessa decisão. Eles se dividem na atividade de preparação. Um dos profissionais determinou: quem prepararia a pipoca e o suco; quem faria a limpeza; como todos deveriam ser servidos. Foi preparada a pipoca e em seguida feito o suco. Um profissional permanecia na porta da copa, controlando para que ninguém se servisse antecipadamente da pipoca, enquanto o suco não estivesse pronto. Num momento em que ele saiu da porta, uma usuária serviu-se de pipoca e saiu da copa. Em seguida foi repreendida publicamente (dedo em riste) pelo profissional por isto. Pronto o suco, foi colocada uma mesa separando a copa da sala. Dois usuários que serviam o suco e a pipoca ficavam do lado de dentro da copa, junto com um profissional; os demais, do lado de fora, pegavam da mesa as canecas com o suco e pipoca e permaneciam na sala comendo. Os diálogos eram raros e fragmentários.

Relato de Observação - Serviço № 1 Uma usuária apresenta-se à recepção como primeira consulta, é então encaminhada para "colher a história" com o enfermeiro. Resumo: Mulher, 49 anos, residente em Cuiabá, acompanhada por amiga/vizinha, conta que trabalha como babá e doméstica desde os 12 anos de idade, morando em casa de estranhos. Nunca teve carteira de tra- balho e nunca, em toda a sua vida, recebeu salário em dinheiro, somente de vez em quando algum trocado para cigarro, doces ou outras miudezas. Há 10 anos mora com uma família para a qual trabalhava em troca de abrigo, comida e roupas. Morava em um quarto nos fundos da casa. A vizinha informa que há alguns meses ela vem apresentando "comportamento diferente", não faz os afazeres domésticos como deveria, é grosseira com a "patroa", não obedece às ordens, às vezes dorme o dia todo. Em vista disso, a patroa não a quer mais, porém, não tem para onde encaminhá-la, uma vez que ela não tem família conhecida. Tem aparência de deficiente mental (grau leve), uma dificuldade moderada de se expressar, porém compreende todas as perguntas feitas, diz que a patroa é que é agressiva com ela, por isso rebelou-se não trabalhando mais. Faz tratamento com cardiologista há vários anos. A vizinha solicita aposentadoria, uma vez que ela "não está bem e não tem como se manter sozinha”. Enfermeiro anota a história na folha de atendimento e a encaminha para o assistente social. Este relatou no prontuário: "Orientei para aguardar consulta médica à tarde. Orientei acompanhante sobre internação para conseguir aposentadoria”, pois com um CID/diagnóstico psiquiátrico aí fica mais fácil o laudo pericial para aposentadoria.

A perspectiva de sujeito-cidadão que se observa nos discursos técnico-políticos da Reforma Psiquiátrica nos parece bastante diferente da implícita nos exemplos. Aqui, observamos um usuário que não participa das decisões terapêuticas, desde as mais simples, como organizar um lanche no seu local de atendimento. Indagamos se a dificuldade é do usuário ou do profissional nessas situações, uma vez que a autoridade exercida por este é tão evidente que não deixa espaço para o trânsito livre dos usuários, controla todos os participantes, tempos e espaços da atividade realizada, como se observa no primeiro registro de observação.

No segundo, a situação de desfiliação ou vulnerabilidade relacional, aliada à precariedade do trabalho (Castel, 1994), é medicalizada para que possa ser absorvida pelo contexto assistencial. O complexo problema físico, emocional e social do "paciente" (ausência de vínculo familiar/relacional/afetivo, exploração sistemática da força de trabalho sem nenhuma garantia de seguridade social, provável deficiência mental, provável doença cardíaca), que resultou em uma "alteração" do comportamento - antes dócil e obediente para o atual insub- 
misso e "indolente" - é visto na perspectiva de que antes era "normal", agora é "anormal". Sendo "anormal", deve ser traduzido para um código do diagnóstico médico para que possa ser abordado (contido) pela via da assistência e corrigido para que volte ao "normal". Todas as expressões de dificuldades nas condições de vida são convertidas em sinais de uma doença. Não se tem aqui nenhuma problematização da condição de cidadania desse usuário. A uma situação de carência de direitos sociais será acrescida a internação psiquiátrica, para a qual concorrerá, provavelmente, o status de periculosidade e estigma próprios dos "doentes mentais" que, devido ao grau de risco social, necessitam ser internados. Assim, estamos referidos nesse quadro à concepção de "cidadania tutelada", pautada pela geração e manutenção de populações que se mantêm à margem do sistema social, pelas políticas sociais de controle e desmobilização da sociedade (Demo, 1995). Mantém-se e aprofunda-se a desigualdade. A assistência está organizada para a manutenção precária da vida e, uma vez que essa não tem mais valor para o trabalho, pode ser descartada.

A dramaticidade dessa situação, ao mesmo tempo em que escancara os mecanismos perversos de exploração na esfera do trabalho, também desnuda a função dos serviços de atenção que, mesmo denominando-se "de atenção psicossocial”, estão claramente identificados com o controle social. Os profissionais/trabalhadores desses serviços estão atuando como agentes da repressão e da manutenção da ordem social e pouco referidos a uma auto-crítica sobre a sua função num aparato tradicionalmente repressivo na sociedade (as instituições psiquiátricas). A percepção de si mesmo como cidadão é, portanto, esvaziada ou ausente, nesses profissionais, como de resto é também em grande parte da sociedade atualmente.

Nessas situações descritas e em várias outras, a complexidade social trazida pelos usuários era rapidamente administrada pela equipe, através da medicalização do problema, com a conseqüente anulação do sujeito-cidadão presente na situação. Resolução essa distante daquela que preconiza a atenção psicossocial da qual nos fala a Reforma Psiquiátrica nos seus princípios e muito semelhante às práticas segregadoras, manicomiais e excludentes, que se pretendia extinguir com a rede de serviços de saúde mental atual. Implícita ou explicitamente nos relatos verbais e nas ações assistenciais dos profissionais que compõem as equipes estuda- das, manifesta-se a alienação de sua responsabilidade técnica, ética e política, como se pode constatar, por exemplo, no fato de que raros profissionais das equipes estudadas, participaram da I Conferência Municipal de Saúde Mental e da II Conferência Estadual de Saúde Mental de Mato Grosso, realizadas em Cuiabá em 2001. Muitos deles não sabiam sequer da realização de ambas ou desconheciam o seu significado. Um dos profissionais, referindo-se à Conferência Municipal de Saúde Mental, informou a um usuário, no seu local de trabalho que: $\mathrm{Na}$ semana que vem, não sei se aqui vai funcionar dia 20 porque vai ter um "negócio" de saúde mental aí, que as pessoas vão, então acho que aqui não vai nem abrir (Profissional № 16).

Foram raros os relatos que denotavam informação adequada sobre a realização e significado das Conferências e Conselhos de Saúde ou que atribuíam alguma importância a essas instâncias de participação política, como o que se observa a seguir: Eu acho muito importante a participação nas Conferências [de Saúde Mental], porque é lá que são definidos os destinos da assistência nessa área, é lá que é referendado, pelos trabalhadores e usuários, a politica (Profissional № 26).

Indicações que davam conta de uma situação de desinformação ou equívocos e alienação em relação às instâncias de participação e controle social na área da saúde foram mais presentes entre os profissionais, e podem ser observados nos relatos abaixo:

Ficam falando de Reforma Psiquiátrica... em Conferência de Saúde Mental... como é que vai reformar alguma coisa se não tem remédio pro paciente ficar em casa!? Eu acho que isso acontece [falta de medicamentos] porque as pessoas que resolvem essas coisas [qual medicamento comprar e em que quantidade] são extremamente burocráticas. Elas fazem as portarias, fazem essas coisas de acordo com uma ideologia própria, regidas pela burocracia, são pessoas de gabinete! Elas não têm a prática e não ouvem quem está na prática! Tem, por exemplo, o Conselho Estadual de Saúde (CES), que deveria tomar uma decisão sobre isso, mas eu não tenho acesso a isso! [desconhecia a representação dos Conselhos Regionais de Medicina, Enfermagem e Psicologia no CES e se surpreendeu ao ser informado sobre isto] (Profissional № 4).

Às vezes eu me pergunto, que bagunça que vai ser... o dia que fechar mesmo os hospitais psiquiátricos e só ficarem os hospitais gerais... vamos ter que fazer alas de psiquiatria dentro dos hospitais 
gerais, porque, vamos dizer que você tem um cardiopata num quarto e um doente começa a gritar no outro, começa a quebrar alguma coisa... e o pessoal sem experiência para conter! [...] O hospital psiquiátrico é o local apropriado para tratar esses pacientes [...] o pessoal de enfermagem não tem medo dos pacientes, de enfrentar, de saber como agir, se aproxima, fala com uma certa dureza. [...] Eu vejo a Reforma Psiquiátrica com olhos de bastante preocupação. Porque tudo neste País, e talvez no mundo, é moda! Lança uma minissaia lá na França e pega a moda no mundo todo, principalmente agora que nós temos uma aldeia global. Então, vamos fazer a Reforma Psiquiátrica! Mas vamos como? Neste País tem essa história, fazem leis maravilhosas e nunca dão condições de exercer essas leis. [...] antes a gente tem que pensar em humanizar a assistência! Depois a gente pensa em Reforma Psiquiátrica, nessa lei, no papel (Profissional № 27).

Evidencia-se, portanto, uma dificuldade dos profissionais se perceberem como sujeitos das decisões técnico-políticas da área. As instâncias de decisão coletiva (no exemplo, o Conselho Estadual de Saúde) eram percebidas como esferas de poder não representativo, não coletivo. Identificam a tomada de decisões técnico-políticas com a "burocracia" e, a partir daí, elas estão fora da esfera de alcance dos profissionais e usuários. Consideram que a instância de decisões é uma abstração - "burocracia", "pessoas de gabinete” - ou que os processos jurídico-legais são "moda". Assim, a Reforma Psiquiátrica é uma "moda" que vem de uma realidade "externa" ao contexto de seu trabalho e da organização da assistência da qual faz parte. Não há, portanto, a evidência de que as mudanças dos processos terapêuticos advêm da crítica a uma determinada maneira de assistir (modelo médico-psiquiátrico) e que, a partir dessa crítica, busca a sua superação. Trata-se de incorporar algo que vem de fora, que impõe modificações que são vistas "com olhos de bastante preocupação", uma vez que modificam aleatoriamente uma realidade percebida como adequada - o tratamento de "doentes mentais" em hospital psiquiátrico, feito por pessoal "que sabe contê-los".

Aos usuários, nesses serviços, resta a submissão à condição de "pacientes". Submetidos a rotinas terapêuticas tecnicamente reducionistas e eticamente desrespeitosas que apontam para ele e seus familiares o seu "lugar" - consumir de maneira acrítica a assistência que o serviço e os profissionais oferecem e agradecer como ficou presente na fala: Bom, aqui... eu não posso dizer nada contra elas [referindo-se aos trabalhadores de enfermagem] eu sou bem atendido... com certeza o que tá no alcance delas ... eu não posso exigir mais, né? [...] elas medem a pressão, aplicam injeção... dão assistência né? [...] Se a gente não está passando bem... de acordo com o medicamento, sempre elas arrumam... dão um jeito de arrumar... medem a pressão.... observam se a pessoa está no seu estado ou não... como está... [...] no dia que vai consultar com o médico, elas medem a pressão [...] aqui, a gente toma o medicamento sem precisar ficar interno, né... [...] Eu acho bom... pelo menos... a gente passa a distrair durante o dia e à noite... a gente tá em casa, né. [...] Porque... com a família... de vez em quando... fico contrariado, perco o sono e mesmo tomando o medicamento eu não consigo... dormir aí que eu fico descontrolado... aí tem que voltar à internação... e agora... qual é o chefe de família, que tem filhos, que não passa contrariedade? E eu sou pai de 13 filhos e ainda criei um casal de netos, são 15 filhos... [...] quando tem acontecido isso: eu ficar descontrolado eu tenho ido direto com o médico, né. Eu tenho ido direto ao médico. [...] Ele dá o encaminhamento. Inclusive eu vim pra tomar o medicamento e voltar e ele achou que eu precisava internar, porque eu estava descontrolado... [...] Foi isso o que aconteceu... [...] Não, ele mesmo não disse nada... eu fui pra internação... a diretoria mesmo ... essa parte ... da medicina... que entendeu que o meu caso era da internação (Usuário № 4).

Embora entremeado de relatos de condutas que apreendem a "doença mental" a partir de uma abordagem essencialmente médica - centrada na medicação, no trabalho médico, na internação - e nos aspectos complementares controle de pressão (quando realizada), ver se tomou o remédio direito, tomar o remédio para não se internar - observa-se um agradecimento implícito ou explícito. Em todos os serviços, foram raros os momentos em que algum usuário expressou qualquer atitude ou verbalização de descontentamento, crítica ou não-concordância com as atitudes terapêuticas. Isso, por si só, mereceria uma auto-crítica institucional e profissional: como é possível lidar com situações tão complexas, estressantes, conflituosas, que envolvem o atendimento de pessoas com problemas mentais e seus familiares, sem que esses conflitos, ou inconformidades, ou divergências sejam explicitados? Não foram observadas situações de impasse ou de crise em relação a isto. Entretanto, algumas informações coletadas no cotidiano dos serviços podem esclarecer 
porque esses conflitos não são evidentes. De observação realizada apresento essa maneira de atuar profissionalmente que determina com que os conflitos (esperados) entre os membros das equipes ou entre os profissionais e usuários/familiares não sejam explicitados como tal.

Relato de Observação - Serviço № $1 \mathrm{Nu}$ ma manhã, um usuário acompanhado por um familiar chegou às 9 h. Não havia mais médico no serviço, pois o que constava na escala do período da manhã havia terminado o atendimento há alguns minutos e havia ido embora. Foi informado por um servidor do setor administrativo que teria que esperar até a tarde para o atendimento. O familiar então perguntou para o servidor, em tom de crítica, qual era o horário do médico. Ele disse, de maneira educada, pausada e ironicamente: "O horário do médico é de quatro horas, no período da manhã, das 7 às 11 horas, mas, como em todo lugar, os médicos daqui chegam, atendem quem tiver marcado e vão embo$r a$, não cumprindo as 4 horas". O usuário escutou calado e em seguida foi embora. O servidor então se dirigiu a mim e disse: "Quando chega alguém assim... olhando no relógio e perguntando o horário do médico... ele tem razão... mas, antes que ele diga algum desaforo pra mim, que estou aqui cumprindo o meu horário, eu já digo logo assim... que ele vai embora. Pro médico eles nunca dizem nada..."

Essa conversa foi presenciada pelo segurança do local que então se aproximou e disse: É assim... Ontem à tarde, o doutor $X$, internou vários pacientes, e tinha um que ficou aqui fazendo cera, conversando com a família, ele e a família dizendo que ainda ia ver se ia internar e tal... Daí a pouco, o doutor $X$ saiu do consultório e disse: "O que é que esse paciente tá fazendo aqui? Eu já internei ele e lugar de paciente internado é lá dentro!" (apontando a porta da internação). Ai, o paciente entrou, a família foi embora... sem discutir mais nada.

Assim, por falta de espaço democrático para expressão, as divergências e conflitos não se evidenciam no cotidiano. Há um clima aparentemente de "harmonia" entre os trabalhadores e entre esses e os usuários. A submissão do mais fraco ao poder do mais forte é tacitamente realizada, em função da percepção da realidade, por parte dos usuários, de que não pode haver qualquer outro encaminhamento para essas situações. Assim, o exemplo acima parece evidenciar que tentar uma aliança com o mais forte é o recurso comumente encontrado pelos oprimidos; a aliança com o usuário - tão pre- judicado e oprimido quanto os servidores de nível médio que permanecem no serviço mesmo na ausência do médico - é descartada em favor de uma observação tácita e implícita de que o mais forte/opressor é inacessível e inatingível e, em sendo assim, resta se aliar a ele na opressão do outro.

Situações de divergência relacionadas a condutas terapêuticas despertavam, geralmente, entre os profissionais, algum descontentamento e a constatação de que não era possível fazer nada para resolvê-las. Em se tratando de serviços que não possuem uma gerência ou coordenação técnica, isso é ainda mais acentuado. Em relação aos usuários, essa divergência só encontrava uma possibilidade de encaminhamento: a submissão do mais fraco ao mais forte. Em ambas, deduz-se uma percepção alienada do processo de trabalho, uma não inclusão da cidadania como conceito norteador da assistência, nem no sentido de possibilitar uma auto-crítica pessoal, profissional, institucional, nem no sentido de incluir a pessoa portadora de sofrimento mental como cidadão - sujeito de direito no seu processo assistencial.

Algum pressuposto de cidadania relacionado a uma concepção assistencialista pode também ser evidenciada em discurso de dirigente, como observa-se a seguir: Para a Reforma [Psiquiátrica] dar certo é preciso que tenha profissionais humanos [...] pessoas que lidam com o outro como companheiro, como colega, como uma relação de seres humanos iguais e não de poder, de profissional e paciente, aquela coisa distante [...] tem que ter um certo envolvimento, você atende o problema mental dele mas você sabe onde ele mora, as condições de vida dele, você auxilia num auxílio-doença, numa cesta básica, num emprego, você tem que ver ele como um todo e pra isso você tem que ter uma certa afetividade, você não pode ver ele só como um diagnóstico (Dirigente № 10).

Nos serviços estudados, práticas que incorporavam no seu fazer terapêutico o resgate da cidadania dos indivíduos acometidos por transtornos mentais ainda eram bastante escassas. Até mesmo discursos mais organizados, denotando responsabilidade técnica e envolvimento político com o dia-a-dia do serviço, com a vivência diária dos usuários no serviço, foram muito raramente expressados pelos profissionais, como mostra a fala:

Faço algumas coisas específicas da minha formação, como atendimento psicoterápico individual, atendimento psicoterápico grupal, contudo, 
eu trabalho com uma técnica chamada psicoterapia breve, (...) onde você estabelece focos de conteúdos que serão trabalhados, pra viabilizar mesmo a própria relação, uma vez que o meu trabatho com eles não se restringe a isso, eu os acompanho em tudo que eu puder acompanhar, na hora da refeição, eu estou junto deles, até porque eu acho importante essa coisa deles terem um ambiente pra comer, deles se sentirem acolhidos, eles têm muito essa coisa de solidão, de ficarem sós, incompreendidos e tal, então eu acho que é importante que eu esteja presente e... em atividades deles mesmo, em oficinas, recreativas, terapêuticas, eu busco participar delas, me envolvendo, no sentido de funcionar como estímulo e de ficar próximo, de estar observando qual o envolvimento deles, porque isso tudo me da material pra eu poder trabalhar, pra eu poder acompanhar, pra eu poder perceber as dificuldades que eles tem, as facilidades... (Profissional № 22).

A análise do trabalho realizado pelas equipes nos serviços estudados aponta para a conclusão de que o processo assistencial-terapêutico encontra-se ainda muito distanciado da inclusão (mesmo terapêutica, quiçá social) e da cidadania do usuário. Mesmo localizando-se em serviços abertos, "não manicomiais" por definição, esses serviços pareciam apresentar uma mudança somente na lógica externa, na visibilidade do equipamento, mantendo práticas não somente custodiais e restritas ao modelo médico-psiquiátrico, mas mais grave, aderido a práticas antiéticas, questionadas pelo próprio saber médico constituído desde Philippe Pinel. Assim, a organização dos serviços parece priorizar apenas o atendimento da lógica de financiamento atual do SUS - a remuneração de serviços de atenção extra-hospitalares.

Sabe-se que as medidas de "tratamento" adotadas ao longo da história da ciência psiquiátrica, serviram, em contextos diversos, a maus-tratos e à "desumanização" de profissionais e pacientes nos hospícios, manicômios ou hospitais psiquiátricos - sinônimos de uma mesma lógica de atendimento. A sua manutenção, de maneira tão visível em contextos formalmente constituídos para a sua superação, é que dá a medida da necessidade de que sejam, cotidiana e competentemente enfrentados os desafios teóricos para compreender a desinstitucionalização como um conceito diferente de desospitalização, como afirmavam Rotelli et al. (1990).

A desospitalização em nada modifica a definição de objeto/objetivos e instrumentos de intervenção prevista no modelo médico psi- quiátrico tradicional. A Reforma Psiquiátrica não pode ser compreendida como um rearranjo administrativo da rede de assistência. A radicalidade de sua proposição, que modifica o objeto de intervenção da "doença mental" abstratamente concebida, para um "sujeito histórico que sofre mentalmente" não pode ser negligenciada. A reforma administrativa e de prédios e a inauguração de serviços extra-hospitalares são medidas que favorecem uma nova abordagem terapêutica, entretanto, é necessário um investimento contínuo e programado em setores menos visíveis como a capacitação e supervisão de profissionais, para que esse novo projeto terapêutico seja alcançado. Prédios novos e portas abertas não garantem projetos terapêuticos que respeitem a cidadania de sujeitos portadores de transtornos mentais.

Alguns estudos têm problematizado o processo de redução da Reforma Psiquiátrica a uma reforma administrativa ou técnico-assistencial (Costa-Rosa, 2000; Torre \& Amarante, 2001; Amarante, 2003). Negando-se ou negligenciando-se as dimensões teórico-conceitual e sociocultural da Reforma, que desconstrói o paradigma médico-psiquiátrico e a conseqüente constituição histórica do não-sujeito da psiquiatria e busca a construção de um novo lugar social da loucura, não se admite o "doente mental” como protagonista. Modifica-se administrativamente a rede de serviços, porém profissionais e usuários mantêm-se alienados num processo de "psiquiatria renovada" ou "clínica modernizada” (Amarante, 2003).

Neste estudo, a alienação - distanciamento político, afetivo, relacional - do profissional em relação ao trabalho é claramente expressada na forma de delimitação e de abordagem de seu objeto de trabalho, como enfatizou-se até aqui: o "doente mental" agora referido como "usuário" continua a merecer consultas rápidas em que se busca essencialmente identificar aspectos psicopatológicos e a ser um consumidor de medicamentos psicotrópicos, que visam essencialmente à contenção de seu sofrimento, compreendido aqui como sintoma. Não se problematiza a diferença entre o conceito de "paciente" e usuário", como se à afirmação semântica diversa correspondesse, automaticamente, uma abordagem de respeito e inclusão.

A referência de cidadania predominante nas transcrições de relatos de entrevistas e nas observações dos serviços estudados é a cidadania tutelada. Apesar de se afirmar de maneira enfática os direitos de cidadãos para os "pa- 
cientes", agora considerados "usuários" dos serviços, parece que essa impossibilidade conceitual ou o paradoxo entre o conceito de cidadania e de "doente mental" não foi adequadamente problematizado pelos técnicos e, conseqüentemente, não resulta em atitudes terapêuticas - profissionais ou institucionais - que possibilitem ou assegurem o posicionamento individual e social do sujeito - doente mental ou usuário do serviço - numa condição plena de cidadania. Ao contrário, observa-se o discurso profissional e institucional neste sentido mas, as práticas terapêuticas são determinadas pelos profissionais com um espaço muito restrito ou mesmo sem nenhum espaço de diálogo com o "paciente"/usuário a esse respeito; e também a finalidade ou o objetivo da terapêutica/tratamento é definida a partir do referencial do profissional e da instituição, com escassa participação do usuário/ "paciente".

\section{Considerações finais}

O movimento de Reforma Psiquiátrica é conformado nos diferentes locais mais ou menos determinado pelo exercício ativo de cidadania de profissionais e usuários dos serviços. A essa conformação - conquistada ou outorgada pela imposição de um novo modelo assistencial corresponderá uma maior ou menor efetividade do exercício de práticas descentralizadas, integradas (e integradoras) e democráticas, que respeitem a pessoa portadora de transtorno mental, enfim, que o inclua como sujeito de sua vida e de seu tratamento ou que perpetue a sua condição de objeto de uma intervenção médico-assistencial, excluindo-o da participação no tratamento e das decisões sobre a sua vida.

Consideramos que a inclusão dos "pacientes" como cidadãos, no processo terapêutico, só será possível na medida em que houver correspondência com a percepção dos "trabalhadores" como cidadãos, nesse mesmo processo de assistência. No paradigma da Reforma Psiquiá- trica é necessária uma redefinição do processo de trabalho das equipes de saúde mental e é no cotidiano, nos confrontos e nas contradições entre o processo de reprodução e recriação, próprios das práticas de assistência à saúde, que pode se dar um processo contra-hegemônico que resgate os envolvidos (trabalhadores e usuários) como sujeitos sociais e cidadãos. Portanto, é principalmente nesse processo cotidiano de trabalho/assistência, que reside a potencialidade implícita de construção de cidadania para trabalhadores e pacientes. É num processo de constituição dos profissionais como sujeitos-sociais que, ao se perceberem criticamente como co-responsáveis por um trabalho coletivo, também se responsabilizam por todos os atos desse trabalho e utilizam (ou não utilizam) as possibilidades de ruptura com os saberes e práticas hegemônicas, que reside a possibilidade de superação das práticas custodiais e burocráticas do trabalho assistencial em saúde mental, presentes ao longo da história (Oliveira \& Alessi, 2003). Percebendo-se como sujeitos/cidadãos integrantes de um aparato institucional que representou, na história da civilização ocidental, um importante mecanismo de controle social, os trabalhadores/profissionais de saúde mental podem se perceber também como agentes de mudança, na medida em que não se resignaram ao papel de agentes da opressão e da exclusão. Entretanto, sem essa consciência das contradições de sua prática, a assistência será encaminhada no sentido de reprodução dessas práticas, ainda que em contextos aparentemente diferentes do manicômio.

Afirmando a Reforma Psiquiátrica como movimento, compreendemos que o "resgate dos direitos de cidadania" dos "portadores de sofrimento psíquico", apresentado pela Reforma Psiquiátrica, necessita de contínua e dedicada exploração de suas contradições. É portanto, essa consciência das contradições de sua prática, que possibilitaria aos trabalhadores constituírem processos terapêuticos que respeitem a cidadania dos "doentes mentais". 


\section{Colaboradores}

AG Bottaro realizou a pesquisa, escreveu e fez a redação do texto. NP Alessi orientou a construção da tese, que originou este artigo, no que tange ao referencial teórico, eleição de categorias analíticas, indicação de bibliografia, sugestões para a análise e revisão geral.

\section{Referências bibliográficas}

Amarante PD (coord.) 1995. Loucos pela vida: a trajetória da reforma psiquiátrica no Brasil. Fiocruz, Rio de Janeiro.

Amarante P 2003. A (clínica) e a Reforma Psiquiátrica, pp. 45-65. In P Amarante (coord.). Archivos de saúde mental e atenção psicossocial. Ed. Nau, Engenheiro Paulo de Frontin.

Bezerra Jr B 1994. De médico, de louco e de todo mundo um pouco, pp. 171-191. In R Guimarães \& R Tavares (orgs.). Saúde e sociedade no Brasil: anos 80 . Ed. Relume-Dumará, Rio de Janeiro.

Bezerra Jr B 1992. Cidadania e loucura: um paradoxo?, pp. 113-126. In B Bezerra Jr \& PD Amarante (orgs.). Psiquiatria sem hospício. Ed. Relume-Dumará, Rio de Janeiro.

Birman J 1992. A cidadania tresloucada, pp. 71-90. In B Bezerra Jr \& PD Amarante (orgs.). Psiquiatria sem hospício. Ed Relume-Dumará, Rio de Janeiro.

Brasil MS 1987. Relatório Final da I Conferência Nacional de Saúde Mental. Brasília.

Brasil MS 1992. Relatório Final da II Conferência Nacional de Saúde Mental. Brasília.

Brasil MS 2001. III Conferência Nacional de Saúde Mental. Caderno de Textos. Brasília.

Carvalho JM 2002. Cidadania no Brasil: o longo caminho. Ed. Civilização Brasileira, Rio de Janeiro.

Castel R 1978. A ordem psiquiátrica: a idade de ouro do alienismo. Ed. Graal, Rio de Janeiro.

Castel R 1994. Da indigência à exclusão, a desfiliação, pp. 21-48. In Saúde loucura 4 - Grupos e coletivos. Hucitec, São Paulo.

Costa-Rosa A 2000. O modo psicossocial: um paradigma das práticas substitutivas ao modo asilar, pp. 141-168.
In P Amarante (org.). Ensaios: subjetividade, saúde mental, sociedade. Fiocruz, Rio de Janeiro.

Delgado PGG 1992a. Reforma psiquiátrica e cidadania. Revista Saúde em Debate 35:80-84.

Delgado PGG 1992b. Pessoa e bens: sobre a cidadania dos curatelados, pp. 99-112. In B Bezerra Jr. \& PD Amarante (orgs.). Psiquiatria sem hospício. Ed RelumeDumará, Rio de Janeiro.

Demo P 1995. Cidadania tutelada e cidadania assistida. Ed Autores Associados, Campinas.

Oliveira AGB \& Alessi NP 2003. O trabalho de enfermagem em saúde mental: contradições e potencialidades atuais. Revista Latino-Americana de Enfermagem 11(3):333-340.

Padrão ML 1992. O estatuto do doente mental. Revista Saúde em Debate 37:11-15.

Pitta AMF \& Dallari SG 1992. A cidadania dos doentes mentais no sistema de saúde do Brasil. Revista Saúde em Debate 36:19-23.

Porter R 1990. Uma história social da loucura. Jorge Zahar Editor, Rio de Janeiro.

Rotelli F, Leonardis O \& Mauri D 1990. Desinstitucionalização uma outra via, pp. 17-60. In F Nicácio (org.). Desinstitucionalização. Hucitec, São Paulo.

Saraceno B 2001. Reabilitação psicossocial: uma estratégia para a passagem do milênio, pp. 13-18. In A Pitta (org.). Reabilitação psicossocial no Brasil. Hucitec, São Paulo.

Torre EHG \& Amarante PD 2001. Protagonismo e subjetividade: a construção coletiva no campo da saúde mental. Revista Ciência \& saúde coletiva 6(1):73-85.

Vieira L 2001. Os argonautas da cidadania. Ed. Record, Rio de Janeiro.

Artigo apresentado em 12/1/2004

Aprovado em 20/7/2004

Versão final apresentada em 9/8/2004 